effusion, or later to its firm union to the chest wall, lungs and diaphragm, as the result of a combined internal and external pericarditis. More rarely the heart may be weakened by invasion of its walls by the tuberculous process, or a miliary tuberculosis may arise by the perforation of the auricle and dissemination of the bacilli by the blood stream, as in Piischmann's's case. Simple embolism, as in Case 8 , might also cause death. Hence it is possible that death may occur in an indirect way from tuberculosis of the lungs by infection of the mediastinal glands and thence of the pericardium, even after the original focus in the lungs is healed, through its effect on the heart. However, the cause of death in tuberculous pericarditis is most often not related to the heart at all, but results from the tuberculosis with which it is associated. Tuberculous pericarditis is generally unaccompanied by any symptoms referable to the heart, and is almost always an autopsy finding.

REFERENCES.

1. William Osler: Am. Jour. Med. Sci., cr, 1893, p. 20.

2. G. Hayem and Paul Tissier: Revue de Méd., ix, 1889, 24.

3. Jaccoud: Semaine Med., xiii, 1893, 21.

4. Breitung: Quoted by Jaccoud, loc. cit.

5. J. H. Sequira : The Lancet, 1898 , ii, 1765 .

6. D. Duckworth : Trans. Path. Soc. of London, xxvi, 1875, 246.

7. H. D. Rolleston : Ibid., xliii, 1892, 20

8. Baginsky : Berl. Klin. Woch., Xxxv, 1898, 1053.

9. H. MrC. Johnson: Phila. Med. Jour., iii, 1899, 231.

10. Fritz Diemer: Zeits. f. Heilkunde, $x x, 1899,257$.

11. C. Bacaloglue : Bull. d. 1. Soc. Anat., 1899, p. 68.

12. Pueschmann: Inaugural Dissertation, Leipsig, 1896 (abstract ed in Cent. f. Allg. Path., viil, 1897, 818).

13. Meltzer : Münch. Med. Woch., xIv, 1898, 1086.

14. W. H. Sheldon: Medicine, v, 1899, 115 .

15. L. Hektoen : Ibld., vii, 1901, 193.

16. G. G. Sears: Boston Med. and Surg. Jour., exxxix, 1898, 293.

17. H. Eichhorst : Correspondenzblatt f. Schweizer Aerzte, Xxv, 1895,385 .

18. F. v. Recklinghausen: Virchow's Archiv, c, 1885, 503.

19. W. C. F. Witte: Phila. Med. Jour., May 7, 1898.

20. Gerrish: Text-book of Anatomy by American Authors, 495.

21. Testut: Anatomie Humaine, ii, 1900, 74

22. Vierordt: Zeits. f. Klin. Med., xili, 1888, 174.

23. Kast: Virchow's Archiv, levi, 1884, 489.

24. Mickle: The Lancet, May 26, 1883.

25. Weigert: Deutsche Med. Woch., 1883, 454.

26. Simmons: Soc. d. Biol. d. Hambourg, 1898, Jan. 14 ; quoted in Gould's Year-Book, 1899, 78.

27. George Blumer: Am. Jour. of the Med. Sci., cxvil, 1899, 19.

28. Henoch: Quoted by Hayem and Tissier, loc. cit.

29. A. N. Peron: Presse Méd., Feb. 19, 1898

30. Samson Gemmell : Glasgow Med. Jour., xliii, 1895, 82.

31. H. Marfan : La Bull. Med. de Paris, xil, 1898, 1183.

32. F. Pick : Zeits. f. Klin. Med., xsix, 1896, 385 .

33. v. Eisenmenger: Wien. Klin. Woch., March 15, 1900, 249.

34. V. Eisenmenger: Zeits. f. Heilk., xxi, 1900 ; Abth. f. Inn. Med.,

H. 1, S. 74

35. Benda : Berl, Klin. Woch., xxxv1, 1899, Nos. 26-29.

36. Ch. Thiry: Presse Med., 1899, No. 104, 374.

37. M. Labbé: Rev, des Mal. d. l. Enfance, xiv, 1896, 280.

38. Valentin : Thèse de Paris, 1894-5, quoted by Labbé.

39. Rosenstein: Zeits. f. Klin. Med., xxxix, 1900, 142

40. Soullard: These d. l. Faculte d. Paris, 1899-1900, abstracted in Gaz. Heb. d. Méd. et Chir., Jan. 14, 1900, p. 44.

41. Cousin: Same as Soullard, p. 46.

42. Hutinel : Rev. des Mal. d. 1. Enfance, xi, 1893, 529, and xii, 15 .

\section{TUBERCULOSIS OF FASCIA.}

\section{J. CLARK STEWART, M.D.}

Professor of Surgical Pathology, Medical Department, University of Minnesota.

MINNEAPOLIS, MINN.

Under this heading I include all cases of primary tubercular infection of the fascia and those cases of fascial tuberculosis secondary to adjacent tuberculosis, in which the fascial involvement is of such an extent as to overshadow the original trouble. There is little to be found on this subject in the surgical text-books, the article in Senn's "Principles of Surgery" having the most extensive consideration. Current medical liter- ature is equally silent, the only noteworthy article which I have seen being that by Dr. J. E. Moore, ${ }^{1}$ which treats the subject most satisfactorily from a clinical standpoint.

\section{CLASSES OF LESIONS.}

In general there are two typical classes of lesions resulting from tubercular infections; these differ widely, and between these extremes there are various gradations. The cold-abscess type resulting from a rather acute infection by the tubercle bacillus, followed by cheesy degeneration, liquefaction. and the formation of an abscess cavity filled with liquid detritus, stands at one extreme. At the other is that class of lesions where, with a more chronic onset, and possibly a smaller dosage, the implantation and growth of the tubercle bacillus results in irritative changes shown by the formation of more or less dense connective tissue overgrowth with or without cheesy foci. It has been too much the custom of surgeons to overlook this latter type, and the non-recognition of the tubercular character of such tissue has caused many operative failures.

In no other form of tuberculosis are the two. types above mentioned more perfectly demonstrable clinically than in inberculosis of fascia. And in no other lesion is the recognition of the form characterized by connec-

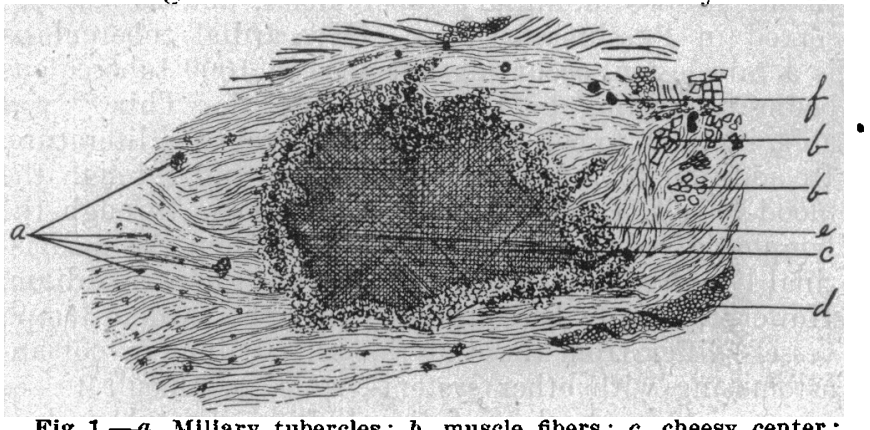

Fig 1.- $a$, Millary tubercles: $b$, muscle fibers; $c$, cheesy center $d$, fat ; $e$, tubercle tissue ; $f$, blood vessel.

tive tissue overgrowth more important both as to diagnosis and for proper treatment. Dr. Moore, in the article cited. recognizes the two classes of fascial tuberculosis, but his division into superficial and deep cases dces not to my mind exactly define the existing difference.

From a pathologic standpoint, I shall divide these cases into two divisions: Class A, acute primary cases with extensive cheesy degeneration as their most marked feature; Class B, chronic, mostly secondary cases, characterized by overgrowth of connective tissue with disseminated areas of caseation. The clinical symptoms of both classes of cases are about the same except that those of the first class give a more acute onset and rapid course. Both come on insidiously with more or less swelling of the affected part and local temperature, and after a time red or bluish discoloration of the skin. Some patients suffer marked pain, and nearly all have a slight afternoon elevation of temperature. After more or less delay the process reaches the surface, and characteristic sinuses are formed giving vent to thin tubercular pseudo-pus. Usually there soon arises pyogenic infection with more marked fever and wasting, and this may occur before the sinuses have opened, causing a clinical picture closely simulating acute phlegmon. DIAGNOSIS.

Diagnosis must be made by exclusion, aided in many cases by operation, and causative lesions in the neighboring bones and joints must be carefully searched for,

1. Jour. AM. Med. AssN., Aug. 12, 1899. 
especially in Class B. where they can almost always be found. In Class A we find, on operation, the familiar cold-abscess between the layers of some extensive fascia, and when, after careful search, no contiguous tubercular lesion can be found in bones, joints, pleuræe and lymph-nodes, our diagnosis becomes established. In such cases the layer of tubercular tissue lining the cavity lies upon a firm connective tissue membrane, and can be scraped therefrom by the sharp spoon, leaving a healthy smooth surface. To illustrate:

CASE 1.-A Swedish street-car conductor, aged 25, came into my service at Asbury Hospital in 1894, with a sinus in the middle of his right calf, discharging bloody puriform fluid. His history was misleading, as he said that he had been well until within a few days, when his leg began to pain him and became swollen. A physician saw him at this time and made an incision, evacuating a large amount of bloody fluid and diagnosing a hematoma. I saw him one week later, at which time there was a sinus with flabby granulations admitting a probe which passed freely to the vicinity of both knee and heel. He had also greatly enlarged lymphnodes in the neck and right axilla.

Under anesthesia the large cavity was opened up by

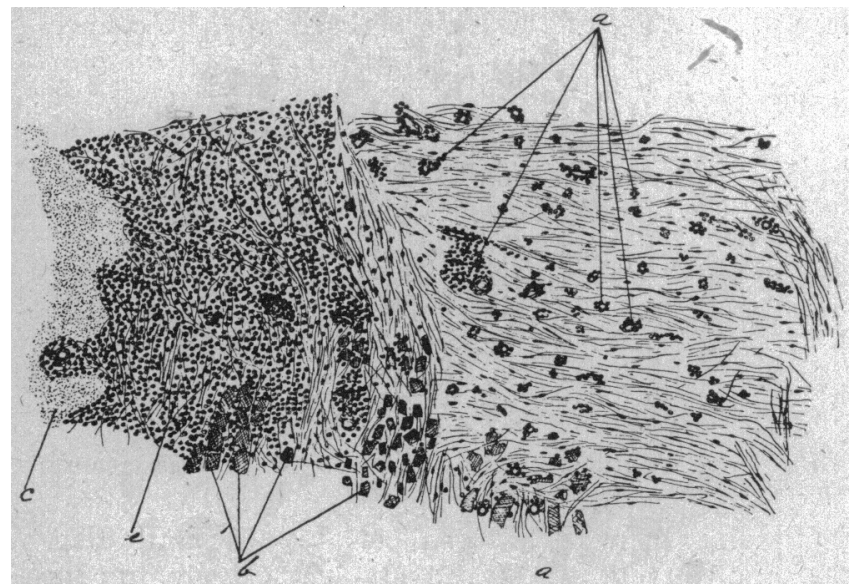

Fig. 2.-a, Small tubercles (mostly perivascular); $b$, degenerate muscle fibers ; $c$, cheesy center; $e$, tubercle tissue.

a median incision reaching from the middle of the popliteal space nearly to the heel. The extensive flaps and the walls of the cavity were then scraped thoroughly with a sharp spoon, until a smooth surface was reached, removing a double handful of tubercular granulations, and revealing an eroded vein as the cause of the previous hemorrhage. The long incision was sutured over iodoform gauze packing; which was removed after forty-eight hours and pressure applied. The large wound healed solidly in ten days, after which I removed the tubercular lymph-nodes in the neck and axilla. $\mathrm{He}$ made a good recovery and is now (1900) alive and well.

The tissue removed was examined microscopically and showed typical, rapidly formed tubercle tissue with many giant cells and a few tubercle bacilli. There was considerable caseous degeneration, and there seemed to be nowhere any attempt to form fibrous tissue.

I have observed this form of fascial tuberculosis only in the calf, thigh, and the muscles of the back, as a primary lesion, or at least without any discoverable adjacent tubercular lesions.

Class B differs greatly both in its gross and microscopic lesions, and the history is much more chronic, and I believe that the majority of these cases coming under this class are secondary to other tubercular lesions.
The important distinguishing feature of these cases is the production of large amounts of fibrous tissue, and the occurrence of the cheesy tubercular material, not in one large cavity limited by a firm fibrous layer, but in multiple small foci which are scattered widely throughout the new-formed fibrous tissue. Such cases can only be relieved by operation with the knife and scissors, instead of the sharp spoon, as every portion of the new fibrous tissue must be removed to insure nonrecurrence. Case 4 , cited in Dr. Moore's article, is the only primary fascial case of this type which I have seen operated on, while the great majority have proved to have other tubercular lesions adjacent as their point of origin.

As I have the gross and microscopic specimens from this case, I will reproduce here the history as given by Dr. Moore in the article cited:

CASE 4.-F. F., aged 48 years, a Mexican coffee planter, came to me in January, 1896, suffering from hydrops articuli of the right knee. The disease, although chronic, was quite mild in character and yielded promptly to the treatment, which consisted of tapping, followed by irrigation with a bichlorid solution and rest in a p'aster cast. Twenty months later, in September, 1897, he returned with a beginning tuberculosis of the fascia of the lower third of the left thigh. There were two sinuses and the disease seemed to be superficial. The part was laid open. free!y seraped, and packed with gauze. On Jan. 10,

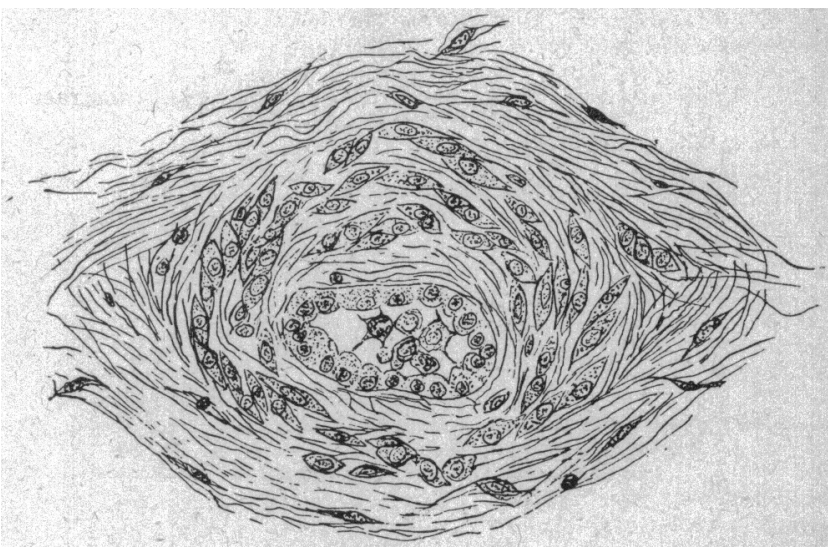

Fig. 3.-Small perivascular tuberele.

1898, I operated a second time, removing all the diseased tissue I could find. On January 29, I realized that the last operation was a failure, and determined to operate again and be as radical as possible. There were at this time several sinuses and a mixed infection and the patient was rapidly failing. I made an incision from just above the knee-joint to the tip of the greater trochanter. At the lower third of the thigh a strip of integument two inches wide and eight inches long, which was perforated by the sinus, was removed. A large portion of the fascia lata was removed, because it was diseased beyond all hope of recovery. The disease was found dipping down into the vastus externus muscle to such an extent that it was necessary to remove the whole of that muscle. It should be noted that this disease was in the left thigh, while the hydrops articuli had been on his right side. The left knee was healthy, but its synovial membrane was being attacked from the outside, and in my efforts to remove all the diseased tissue I opened into the upper pouch of the knee. A piece of synovial membrane two inches long and one inch wide was removed. and the opening into the joint immediately closed with a running catgut suture, and although the patient was suffering from a mixed infection at the time of operation, no joint symptoms followed. This enormous wound was closed; and with the exception of a small spot at the lower end, where there was a small slough, it healed by first intention.

The slough soon separated, and the wound granulated over without return of tuberculosis. The patient left the hospital in less than three weeks, and very soon after returned to his Mexican home. Before he left he walked into my office with a cane, and the function of his limb was remarkably good considering the amount of tissue removed. 
In May, 1899, I received a report that his leg was giving hin no trouble, but that his general health was failing and that he had a cough.

Please note that while this case was primary in the fascia, it was only after recurrence that it took on this more disseminated form.

CAse 2.-A robust looking Swedish farmer, aged 30, was admitted to my Asbury Hospital service, with a clear case of caries sicca of the right shoulder, of some months' duration. In addition there were several sinuses about the joint, not leading to bone, or to the joint. On operation there was found a diffuse tuberculosis of the fascia about the shoulder, including the intermuscular septa between the muscles of the post-scapular group. All the new tissue was removed by an extensive dissection, and the wound soon healed except a sinus which now for the first time led to bare bone near the joint. At a later date this was followed to the head of the humerus, which was excised, after which the sinus closed. He recovered with a useful arm and has remained well up to the present time, five years after the beginning of his tuberculosis.

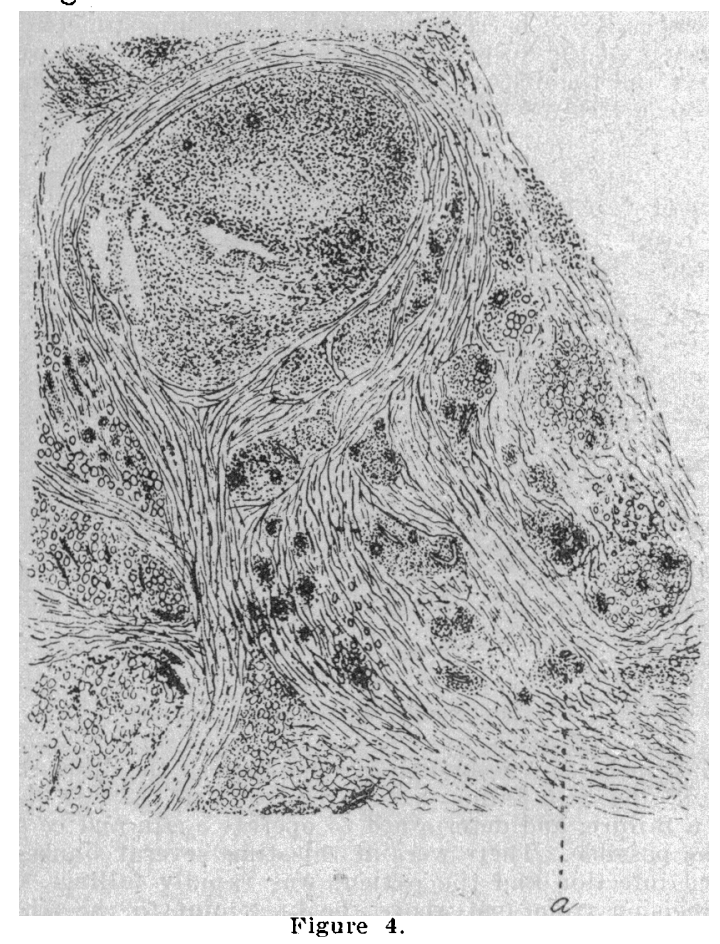

CASE 3.-A more recent case illustrates well the early stages of this interesting process. A woman of 30 , after a general septicemia due to an abortion. developed an osteomyelitis of rather mild type which resulted in an enlargement of the lower third of the femur, without sequestra or sinuses. She had little trouble for four years, when she came in with what she called a boil on her thigh over the enlarged bone. This was incised and a small sequestrum, a mere splinter, taken out; there was then noted an induration about the sinus, and extending a short distance down the thigh. Two weeks later she was operated on under anesthesia, and on incision a mass of tissue as large as a goose-egg was found surrounding the sinus and extending some distance along the fascial planes. The small sinus led through this mass into the femur where there was a tubercular deposit one-half inch in diameter, situated in the new osteomyelitic bone. This was chiseled out so as to form a smooth-walled cavity of conical form, packed with gauze, and the patient made a slow but uneventful recovery.

On section of the removed tissue, it was found to consist of quite cellular new connective tissue containing numerous small cavities filled with gelatinous-looking tubercle tissue which had not as yet undergone cheesy degeneration.

CASE 5.-Through the kindness of my colleague in the university, Dr. S. M. White, I am able to show the microscopic findings in a still more recent case than any reported. While making an autopsy on a tubercular subject, Dr. White infected the middle finger of his left hand, at the site of a small wart on the palmar surface. About two weeks after infection there formed a small abscess which contained.staphylococcus pyogenes aureus. The abscess healed, but after a few weeks a swelling appeared on the back of the finger and gradually increased in size until, in February, 1900, there was a diffuse enlargement of the finger, mainly along dorsum.

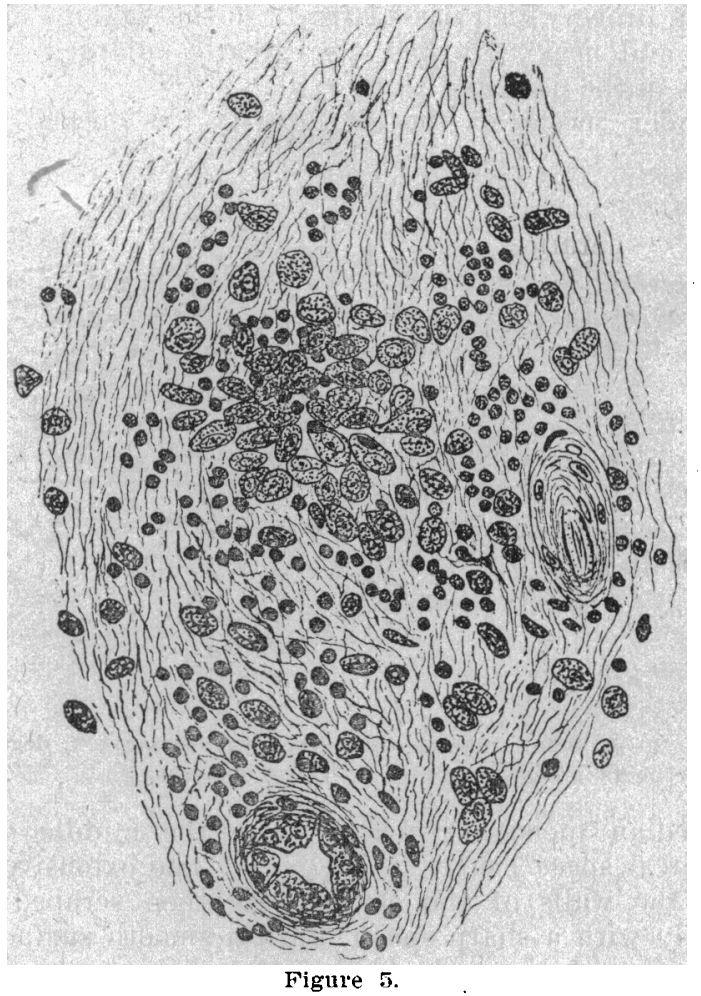

Various methods of treatment were used without avail until March 3, 1900. At this time I operated under cocain, and dissected away a saddle-shaped piece of fibrous tissue about three-sixteenths of an inch thick at the center. It was grayish, and succulent, but gave no macroscopic signs of tuberculosis. This tissue had to be dissected away very carefully from the capsule of the joint and the sheath of the extensor tendons, and had so involved the latter that in one or two places small openings were made into the lumen of the sheath. The wound was sutured and healed per primam. There has been no recurrence up to date.

Sections of this tissue show new connective tissue rich in cells, with many aggregations of round and polyhedral cells, but no cheesy degeneration. A piece of this tissue was emulsified with sterile broth and injected into the peritoneal cavity of a guinea-pig. It died tubercular and tubercle bacilli were demonstrated in the lesions found at autopsy. 
This second form of fascial tuberculosis is vastly more serious than the first, as it regularly involves the intermuscular septa, and the sheaths of tendons and muscles, and passes easily to adjacent joints.

A successful operation against these cases must often be most extensive, and a neglected case will occasionally demand an amputation when an extremity is affected, or prove irremediable when upon the trunk. Neglected cases of the first type may pass into the second, but when operated on promptly and thoroughly, they heal rapidly and do not relapse.

A case seen two years ago, in the service of Dr. F.A. Dunsmore, illustrates how a fascial tuberculosis springing from an insignificant bone lesion, undiagnosed and untreated, may baffle conservative surgery. The case was a woman of 40 , from outside the city. The history was fairly acute, and gave no indication of the bone lesion. The lesions present were a gèneral tuberculosis of the fasciæ of the forearm, including intermuscular septa, tendon sheaths and even the interosseous membrane, all of which arose from a small chronic tubercular focus in the lower end of the radius. The arm was swollen to three times its natural size, and gave me the impression of a rapidly-growing sarcoma, but on incision there was only found a gelatinous connective tissue everywhere, with only an occasional cheesy focus.

Any operation here, to be successful, would have necessitated the removal of all the fascia, together with all the connective tissue covering the muscles, vessels, etc., and was plainly impossible, so the arm was amputated.

I am inclined to believe, after a careful study of a number of these cases, that those of the first class are caused by a rapid and simultaneous infection of the wide fascial planes by the tubercle bacilli, as the lesions appear to be all of one age and are without the connective proliferation characteristic of the more chronic tuberculoses. The lesions correspond quite closely to those seen when a joint is infected by the rupture into its cavity of a cheesy bone focus, with the rapid spread over the synovial surface of a large amount of tuberculous material. Those of the second class, on the contrary, resemble primary joint tuberculosis, where the infection has arisen at one point and spread gradually over the joint tissues. Here we have lesions of various ages, but always the characteristic fibrous tissue, containing more or less widely scattered cheesy foci, or in more recent cases non-cheesy tubercular tissue.

The proportion of the connective tissue to the cheesy foci varies according to the chronicity of the process, there being cases (Case 5, cited) where the naked eye shows no indication of the tuberculosis. but merely great overgrowth of connective tissue, but where the microscope and animal inoculation prove the presence of tuberculosis. In other cases the cheesy foci predominate and attain fairly large size, but they never, I think, in this form reach a size entitling them to be called cold abscesses.

Through the courtesy of Dr. and Mrs. Nickerson, my colleagues in the medical department of the University of Minnesota, I am able to illustrate this article with drawings which quite satisfactorily fill the place of the secions shown when the paper was originally read. Cuts 1, 2 and 3 are from Dr. Moore's Case No. 4. Cut 1 is a somewhat schematic, low-power drawing, showing a large cheesy focus, surrounded by tubercle tissue, the whole being enclosed in dense fibrous tissue containing scattered tubercles. Cut 2 is from the same section under higher power, and shows the details of the tuber- cular zone about the cheesy center, and also very well the scattered tubercles in the dense connective tissue area.

Cut 3 shows a beginning perivascular tubercle like any of those marked " $a$ " in Cut 2 ; the obliterating tubercular endarteritis, and the concentric arrangement of the epithelioid cells about the artery are well shown in this tubercle.

Cuts 4 and 5 are made from a section of the tissue removed from Dr. White's finger. Cut 4 shows the lower power appearance of what seemed to the naked eye to be normal fibrous tissue. A large tubercle is shown in which cheesy degeneration is just beginning, and numerous smaller tubercles.

Cut 5 shows the details of the small tubercle "a" of Cut 4. There is here merely a massing of oval epithelioid cells and leukocytes, without the regular arrangement seen in the more slowly formed tubercles of Cut $\therefore$ The vessels seem to be taking a part in the process, as shown by the swollen and proliferating endothelial cells, but there are no well-formed perivascular tubercles.

$$
\text { SUMMARY. }
$$

1. Tuberculosis of the fascia occurs with sufficient frequency to entitle it to more attention than it has received in the past. 2. It occurs in two well-marked forms. 3. The recognition of these forms is essential to its proper surgical treatment. 4. Fibrous tissue associated with, and resulting from tubercular infection is to be viewed as tubercular tissue, and treated accordingly. 5. Such fibrous tissue may in some cases need the test of animal inoculation to absolutely prove its tubercular character. 704 Dayton Building.

\section{SARCOMA OF THE PANCREAS.*}

(From the Laboratory of Pathology of the Chicago Policlinic.) GEORGE A. BOYD, M.D. BALDWIN, KAN.

Litten $^{1}$ was the first to report a primary sarcoma of the pancreas in which the microscopic findings were recorded. His ease occurred in a boy 4 years old. The tumor weighed fifteen pounds. Virchow made the microscopic examination and found a small round-celled sarcoma. This was in 1889 .

Senn, ${ }^{2}$ in 1886, reported two cases of sarcoma of the pancreas; one from Mayo's "Outlines of Human Pathology," published in 1836. As this was probably the first case of primary sarcoma of the pancreas it will

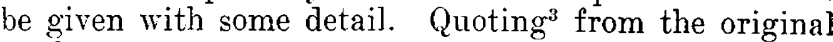
work :

Malignant disease rarely attacks the pancreas alone but involves in common with it either the stomach or liver or both.

A gentleman, aged 35, died after an illness of about eighteen months duration in which it was to the last impossible to say what organ was the scat of the disease. His complaint began with a febrile attack which left him weak and from that time he was liable to dyspeptic symptoms with variable appetite and an undefined uneasiness in the epigastric region. He gradually lost strength and flesh and when he consulted Dr. Newbegging in January, 1822, he was found thin and weak; but Mr. N. was particularly struck with his remarkable paleness, even his lips and the inner surface of his mouth was entirely without color. About this time he had some vomiting and was feverish for a day or two. . . . When I saw him in April he was reduced to the last degree of palencss and debility but his pulse was full, strong, and regular. . . . He died at the end of April without any change of symptoms except that his pulse became frequent a few days before his death. 